\title{
Allopregnanolone Promotes Neuronal and Oligodendrocyte Differentiation In Vitro and In Vivo: Therapeutic Implication for Alzheimer's Disease
}

\author{
Shuhua Chen $^{1} \cdot$ Tian Wang $^{1} \cdot$ Jia Yao $^{2} \cdot$ Roberta Diaz Brinton ${ }^{1,3,4}$ (D) \\ Published online: 6 July 2020 \\ (C) The American Society for Experimental NeuroTherapeutics, Inc. 2020
}

\begin{abstract}
Previous studies demonstrated that the endogenous neurosteroid allopregnanolone (Allo) promotes regeneration of rodent and human neural progenitor/neural stem cells (NSCs) in vitro and in vivo, and restores neurogenesis and cognitive function in the male triple transgenic mouse model of Alzheimer's disease (3xTgAD). In this study, we investigated Allo regulation of neuronal differentiation of adult mouse neural stem cells from both sexes. Outcomes indicated that the age-dependent shift from neuronal to glial differentiation was accelerated and magnified in 3xTgAD adult NSCs compared to that in age-matched non-Tg NSCs. Coincident with the decline in neuronal differentiation, the number of immature neurons declined earlier in 3xTgAD mice, which was consistent with observations in the aged Alzheimer's human brain. Allo treatment restored the neuron/astrocyte ratio derived from adult 3xTgAD NSCs and increased both NSC proliferation and differentiation in the 3xTgAD brain. Allo treatment also significantly increased expression of Olig2, an oligodendrocyte precursor cell marker, as well as Olig2-positive cells in the corpus callosum of 3xTgAD mice. Increased neuronal and oligodendrocyte differentiation was paralleled by an increase in the expression levels of insulin-like growth factor-1 (IGF-1) and IGF-1 receptor (IGF-1R). Collectively, these findings are consistent with Allo acting as a pleiotropic therapeutic to promote regeneration of gray and white matter in the Alzheimer's brain.
\end{abstract}

Key Words Allopregnanolone $\cdot$ neurogenesis $\cdot$ neuronal differentiation $\cdot$ oligodendrogenesis $\cdot$ Alzheimer's disease

\section{Introduction}

Neural stem cells (NSCs) retain the capacity of proliferation and differentiation to generate new neurons in the adult mammalian brain $[1,2]$. Adult neurogenesis occurs mainly in the

Electronic supplementary material The online version of this article (https://doi.org/10.1007/s13311-020-00874-x) contains supplementary material, which is available to authorized users.

Roberta Diaz Brinton

rbrinton@email.arizona.edu

1 Center for Innovation in Brain Science, University of Arizona, 1230 N Cherry Avenue, Tucson, AZ 85721, USA

2 Department of Pharmacology and Pharmaceutical Science, School of Pharmacy, University of Southern California, Los Angeles, CA, USA

3 Department of Pharmacology, College of Medicine, University of Arizona, Tucson, AZ, USA

4 Department of Neurology, College of Medicine, University of Arizona, Tucson, AZ, USA subgranular zone of the hippocampal dentate gyrus (SGZ) [3-5] and the subventricular zone (SVZ) along the lateral ventricles $[6,7]$, but can also occur in other brain regions including the cortical layers [8], hypothalamus [9], and cerebellum $[10,11]$. Although relatively few new granule neurons are generated in the adult hippocampus, the cells are functionally capable of survival and integrate into the brain circuitry [12].

However, the regenerative potential of adult NSCs declines with aging [13-15], which is much more prominent in patients with Alzheimer's disease, correlating with accelerated decline in neural plasticity and cognitive function [2, 16-20]. Given the important role of neurogenesis in maintaining synaptic plasticity and memory formation in the adult brain [21], promoting the regeneration of neurons and neural circuitry may be a promising therapeutic strategy to maintain or restore cognitive function in $\mathrm{AD}$ patients [22].

In addition, $\mathrm{AD}$ is also associated with myelination abnormalities in vulnerable brain regions, including the hippocampus and cortex [23]. Clinically, white matter degeneration is observed in brain regions when $\mathrm{AD}$ patients are at the incipient stage $[24,25]$. In the triple transgenic mouse model of 
familial Alzheimer's disease (3xTgAD), white matter abnormalities and loss of axonal integrity occurred in the same brain regions vulnerable to $\mathrm{AD}$ pathology, which correlated with decreases in neurogenesis and cognitive function [26, 27]. Thus, white matter abnormalities are important components of $\mathrm{AD}$ pathogenesis and could be a potential therapeutic target.

Allopregnanolone (Allo), an endogenous neurosteroid, has been shown by our previous studies to significantly increase proliferation of both rodent and human neural stem/neural progenitor cells in vitro [28] and neurogenesis within the SGZ and SVZ in the 3xTgAD brain in vivo [29, 30]. Allo has also been reported to increase myelin basic protein in organotypic slice cultures of rat cerebellum [31] and delay demyelination in Niemann-Pick C mice [32]. Functionally, Allo reversed the learning and memory deficits of $3 \times \mathrm{TgAD}$ mice prior to and following the onset of AD pathology, and was comparably efficacious in normal aged mice [33].

Reported herein is an analysis of the impact of Allo on differentiation of adult mouse NSCs. The outcome of this analysis demonstrated accelerated decline in neurogenesis in the male 3xTgAD mouse brain, which was accompanied by the age-dependent shift of neuronal to glial differentiation of NSCs. These findings are consistent with observations in the aged Alzheimer's human brain [2]. Allo treatment restored neuronal differentiation of adult $3 \times \mathrm{TgAD}$ NSCs in vitro and promoted neurogenesis in both major neurogenic compartments of the adult $3 \mathrm{xTgAD}$ brain in vivo. Further, Allo treatment also enhanced oligodendrogenesis in the adult $3 \times \mathrm{TgAD}$ brain. Collectively, these findings provide mechanistic rationale for Allo-induced restoration of cognitive function in a mouse model of AD and are consistent with Allo acting as a pleiotropic regenerative therapeutic to prevent or delay neurogenic deficits associated with Alzheimer's disease.

\section{Methods}

\section{Neural Stem Cell Culture}

Adult mouse neural stem cell cultures were derived from hippocampal tissue of 3- to 6- and 15-month-old 3xTgAD and non-Tg mice. Cell suspension was obtained by using a NeuroCult ${ }^{\mathrm{TM}}$ Enzymatic Dissociation Kit (StemCell Technologies, Vancouver, BC, Canada; 05715). Briefly, hippocampal tissue was minced to small pieces and incubated in dissociation solution at $37{ }^{\circ} \mathrm{C}$ for $7 \mathrm{~min}$. Inhibition solution was then added, and the suspension was centrifuged. The pellet was resuspended with resuspension solution and mechanically dissociated with plastic tips (P200 then P1000). The cell suspension was filtered through a $40-\mu \mathrm{m}$ cell strainer to remove any clumps and debris. The cells were then counted using trypan blue and cultured in T-25 flasks in a humidified incubator $\left(37{ }^{\circ} \mathrm{C}\right.$ and $\left.5 \% \mathrm{CO}_{2}\right)$. Primary neurospheres $(6 \times$

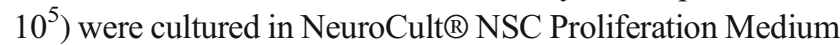
(StemCell Technologies, 05702), consisting of basal medium supplemented with $20 \mathrm{ng} / \mathrm{ml} \mathrm{EGF,} 10 \mathrm{ng} / \mathrm{ml}$ basic FGF, and $2 \mu \mathrm{g} / \mathrm{ml}$ heparin. A partial fresh medium was replaced every 2 to 3 days. Neurospheres were passaged and subcultured every 3 to 4 days. Cultures were used for experiments between passages 2 to 5 .

\section{Neural Stem Cell Culture Characterization}

To characterize the NSCs cultured in our lab, the NSCs from neurospheres were seeded on glass coverslips coated with poly-D-lysine/laminin to form adherent monolayer cultures and incubated in proliferation medium for 2 days. The monolayer NSCs were then fixed in 4\% paraformaldehyde and immunofluorescence labeled with Nestin (Abcam, Cambridge, UK; ab24692; 1:200) and $\beta$-tubulin (Tuj1; Covance, Princeton, NJ; MMS-435p, 1:500) antibodies. To verify the differentiation capacity of the adult NSCs, the monolayer NSCs were cultured in NSC differentiation medium (StemCell Technologies, 05704), consisting of basal medium and differentiation supplement, for 7 days. Cells were then fixed in 4\% paraformaldehyde and immunofluorescent labeled with anti-microtubule-associated protein (MAP2) mouse antibody (Sigma M4403; Darmstadt, Hesse, Germany; 1:500), anti-glial fibrillary acidic protein (GFAP) rabbit antibody (Dako Agilent, Santa Clara, CA, USA Z0334, 1:500), and anti-myelin basic protein (MBP) rabbit antibody (Millipore AB980; Darmstadt, Hesse, Germany; 1:500). Fluorescenceconjugated secondary antibodies (FITC-conjugated goat antimouse and $\mathrm{Cy} 3$-conjugated goat anti-rabbit) were used for visualization. Nuclei were counter stained with 4,6diamidino-2-phenylindole (DAPI). Images were captured with Axiovert 200 M Marianas Digital Fluorescence Microscopy Workstation (Intelligent Imaging Innovations, Denver, CO).

\section{Animals}

Animal experiments were conducted as approved by the University of Southern California Institutional Animal Care and Use Committee (IACUC). Colonies of 3xTgAD (homozygous mutant of human APPswe, tauP301L and PS1M146V) mouse and non-Tg mouse strain pairs (C57BL6/129S; gift from Dr. Frank LaFerla, University of California, Irvine) [26] were bred and maintained at the vivarium of the University of Southern California (Los Angeles, CA) following National Institutes of Health guidelines on use of laboratory animals. Mice were housed at $22{ }^{\circ} \mathrm{C}$ on $12-\mathrm{h}$ light/dark cycles and provided with ad libitum access to food and water. Mice were genotyped at every generation to confirm the genotype. Data reported were derived from male mice with the exception of analyses conducted using mouse- 
derived neural stem cells which were pooled from female and male mice.

\section{Drug Preparation and Treatment}

Allopregnanolone (Allo; $3 \alpha$-hydroxy-5 $\alpha$-pregnan-20-one) was purchased from Steraloids, Inc. (Newport, RI). For in vitro treatment, Allo stock solution $(10 \mathrm{mM})$ was prepared in ethanol and diluted in culture medium to $100 \mathrm{nM}$ with $0.001 \%$ ethanol concentration. Ethanol at $0.001 \%$ was used as vehicle control. For in vivo study, Allo $(2.5 \mathrm{mg})$ was dissolved in $50 \mu \mathrm{l}$ ethanol and diluted with $950 \mu \mathrm{l}$ PBS $(2.5 \mathrm{mg}$ Allo/ $50 \mu \mathrm{l}$ ethanol/950 $\mu \mathrm{l} \mathrm{PBS}$ ) to a final ethanol concentration of 5\%. Allo solution was subcutaneously injected into 5month-old male $3 \times \mathrm{TgAD}$ mice at $10 \mathrm{mg} / \mathrm{kg}$ body weight $(0.25 \mathrm{mg} / 100 \mu \mathrm{l} / 25 \mathrm{~g}$ mouse) once per week for 2 weeks. Five percent ethanol was injected as vehicle control. Following each Allo treatment, thymidine analogue, 5-bromo-2'-deoxyuridine (BrdU, purchased from Sigma-Aldrich, St. Louis, MO), was administrated intraperitoneally (IP) at $100 \mathrm{mg} / \mathrm{kg}$ in 2 doses. A total of 4 doses of BrdU were incorporated in the study.

\section{Animal Dissection and Tissue Collection}

Upon completion of treatments, animals were analyzed at 5 to 6 months of age. Mice were first anesthetized by intraperitoneal (IP) injection of a mixture of ketamine and xylazine and then transcardially perfused with ice-cold phosphate-buffered saline (PBS). Brains were rapidly removed and placed on ice. Hippocampus and cortex were dissected out, kept on dry ice, and then stored at $-80{ }^{\circ} \mathrm{C}$ for Western blot and flow cytometric studies. For immunohistochemistry analysis, subgroups of mice were transcardially perfused with PBS followed by $10 \%$ formalin solution. Brains were removed, postfixed overnight in $10 \%$ formalin, and processed to either $6-\mu \mathrm{m}$ paraffin sections by the Histology Lab from USC School of Pharmacy core facilities or $40-\mu \mathrm{m}$ free-floating multibrain sections by NeuroScience Associates (Knoxville, TN).

\section{Immunohistochemistry}

Coverslips or sections were blocked in $5 \%$ normal goat serum in PBS containing $0.3 \%$ Triton X-100 for $60 \mathrm{~min}$, then incubated with primary antibody overnight at $4{ }^{\circ} \mathrm{C}$. Cultured cells on coverslips were double labeled with MAP2 and GFAP as described in the section "Neural Stem Cell Culture Characterization." Paraffin sections need to be first deparaffinized and rehydrated, followed by antigen retrieval in $10 \mathrm{mM}$ sodium citrate buffer ( $\mathrm{pH}$ 6.0) using a steamer before staining. The following antibodies were used: monoclonal rat anti-BrdU (AbD Serotec, Oxford, UK; MCA2060) 1:400, rabbit polyclonal anti-DCX (Cell Signaling, Danvers,
MA; \#4604) 1:500, mouse anti-NeuN (Millipore, MAB377) 1:1000, rabbit anti-Olig2 (Millipore, AB9610) 1:500, rabbit polyclonal anti-IGF-1 (Abcam, ab9572) 1:200, and rabbit polyclonal anti-IGF-1R (Millipore, 04-298) 1:200. Signals were detected using Alexa Fluor 488 goat anti-rat, Alexa Fluor 555 goat anti-mouse, or anti-rabbit secondary antibodies. Nuclei were stained with DAPI. Images were captured with the Axiovert 200 M Marianas Digital Fluorescence Microscopy Workstation (Intelligent Imaging Innovations, Denver, CO). All analyses were performed with the experimenter blinded to the condition.

\section{Flow Cytometric Analyses}

\section{Cell Isolation and Fixation [34]}

Frozen hippocampus or cortex was thawed in cold PBS/ EDTA solution. Small pieces of thawed tissues were mechanically dispersed using $100-\mu \mathrm{m}$ and $35-\mu \mathrm{m}$ nylon cell strainers (BD Bioscience, Franklin Lakes, NJ \#352360 and \#352235). Briefly, the tissue suspension was first pressed through the $100-\mu \mathrm{m}$ mesh strainer using the plunger of a 1-ml syringe. Importantly, the mesh was placed in a tissue culture dish containing PBS/EDTA, such that the bottom of the mesh was in contact with the surface of the liquid. This configuration allowed the cells to be immediately released into buffer. The mesh was then rinsed several times with $4{ }^{\circ} \mathrm{C}$ cold PBS/ EDTA. The resulting cell suspension $(2-5 \mathrm{ml})$ was then filtered through a $35-\mu \mathrm{m}$ cell strainer, and the total volume was adjusted with PBS/EDTA to $10 \mathrm{ml}$ per sample. Resulting cell suspensions can be kept on ice for up to 20 min while other tissue samples were processed. After centrifugation $(310 \times \mathrm{g}$ at $4{ }^{\circ} \mathrm{C}$ for $6 \mathrm{~min}$ ) and removal of the supernatant, the cell pellet was suspended in $0.6 \mathrm{ml}$ of $4{ }^{\circ} \mathrm{C}$ cold PBS/EDTA. To fix the cells, $1.4 \mathrm{ml}$ of $100 \%$ ethanol $\left(-20^{\circ} \mathrm{C}\right.$ cold $)$ was added drop-wise under constant, gentle vortex. Samples were incubated in ethanol for $30 \mathrm{~min}$ on ice and then overnight at $20{ }^{\circ} \mathrm{C}$ before being subjected to staining.

\section{Labeling}

Cell suspensions were removed from $-20{ }^{\circ} \mathrm{C}$ storage and allowed to thaw to room temperature for $10 \mathrm{~min}$. After centrifugation $(310 \times \mathrm{g}$ for $6 \mathrm{~min})$, pellets were resuspended in $2 \mathrm{ml}$ of wash buffer (PBS containing 0.5\% BSA) and incubated for $5 \mathrm{~min}$. To expose BrdU epitopes, collected pellets were resuspended and incubated with $2 \mathrm{~N} \mathrm{HCl}$ at $37^{\circ} \mathrm{C}$ for $20 \mathrm{~min}$, followed by incubation in $0.1 \mathrm{M}$ borate buffer for $2 \mathrm{~min}$ at room temperature to neutralize the acid. The nuclei were then washed and incubated in the following fluorescenceconjugated antibodies: mouse monoclonal FITC-conjugated anti-BrdU antibody (BD Biosciences, Cat \# 347583) and rabbit polyclonal Cy5-conjugated anti-NeuN antibody (Bioss 
Antibodies, Woburn, MA, Cat \# bs-1613R-Cy5) for 50 min at room temperature in the dark. The nuclei were then washed twice with wash buffer and stained with propidium iodide (PI) before flow cytometry measurement.

\section{Flow Cytometry}

BD LSR II flow cytometer system with BD FACSDiva software (BD Biosciences) was used to perform the flow cytometry assays. The PI positive particles were gated as P1. Nuclei stained for BrdU and NeuN were quantified from P1 subset gating. Gate Q-2 were BrdU positive nuclei; gate Q2-1 were BrdU and NeuN double positive nuclei.

\section{Western Blotting}

Frozen hippocampus or cortex from mouse brains were homogenized using the Bullet Blender (Next Advance, Troy, NY; Cat \# BBX24B), and protein lysates were prepared in Tissue Protein Extraction Reagent (T-PER) (Thermo Scientific, Waltham, MA; Cat \# 78510). An equal amount of protein $(20 \mu \mathrm{g})$ was loaded in each well of $12 \%$ SDS-PAGE gels (Bio-Rad Laboratories, Hercules, CA), electrophoresed with Tris/glycine running buffer, and transferred to polyvinylidine difluoride membrane $(0.45 \mu \mathrm{m}$ PVDF). The blots were probed with rabbit polyclonal anti-doublecortin (DCX) (Cell Signaling, Cat \# 4604, 1:1000), rabbit polyclonal anti-Olig-2 (Millipore, Cat \# AB9610, 1:1000), rabbit polyclonal anti-IGF-1 (abcam, ab9572, 1:500) or rabbit polyclonal anti-IGF-1R (Millipore, 04-298, 1:200), and the corresponding HRP-conjugated goat anti-mouse or goat anti-rabbit secondary antibody (Vector; Burlingame, CA) at a concentration of $1: 5000$ to $1: 10,000$. Anti- $\beta$-actin (Millipore, Cat \# MAB1501, 1:5000) was used as a control for protein loading. The protein bands were visualized using Pierce SuperSignal West Pico Chemiluminescent Substrates (Thermo Scientific, Cat \# 34078) and captured by Molecular Imager ChemiDoc XRS System (Bio-Rad Laboratories). All band intensities were quantified using the Image Lab software and calculated by normalizing to $\beta$-actin.

\section{Statistics}

Data were plotted as scatter plots with mean $\pm 95 \% \mathrm{CI}$. Unpaired $t$ test was used to compare the differences between 2 independent groups, such as non-Tg versus 3xTgAD (Fig. 2B) or Veh versus Allo (Figs. 3, 4, 5B, C, D, 6, 7A, B). One-way ANOVA was used to compare the variance in the group means with only 1 independent variable, and the differences between any 2 groups were further determined by Tukey's multiple comparison test (Fig. 2A). $p$ values were provided in both "Results" section and figures.

\section{Results}

\section{Characterization of Adult Neural Stem Cell Self- Renewal and Differentiation}

We first confirmed that in vitro adult mouse NSCs maintained the capacity for neurosphere formation and the differentiation into 3 neural lineages (neurons, astrocytes, and oligodendrocytes). As shown in Fig. 1A, B, neurosphere formation was detectable after 2 days in proliferative medium (Fig. 1A), and neurosphere size increased with days in culture (Fig. 1B), indicating self-renewing capacity of adult mouse NSCs in vitro.

The cellular composition of generated neurospheres was further analyzed in adherent monolayer cultures. When cultured in proliferative medium, the majority of cells were positive for Nestin, a marker for progenitor cells (Fig. 1C); Tuj1, a neural specific marker, was also detected in a subset of cells (Fig. 1D). Following 5 to 7 days of culture under differentiation conditions, differentiation of NSCs into 3 neuronal lineages was apparent, indicated by positive staining of MAP2 (neuron marker), GFAP (astrocyte marker), and MBP (oligodendrocyte marker), respectively (Fig. 1E, F). Together, these data confirmed that adult mouse NSCs possessed the ability for self-renewal and differentiation towards all 3 neural lineages in vitro.

\section{Age-Dependent Decline in Neuronal Differentiation Was Accelerated in Adult 3xTgAD NSCs and Brain}

The impact of age and Alzheimer's pathology on differentiation capacity of adult NSCs was assessed using NSCs derived from non-Tg and 3xTgAD mice at 3, 6, and 15 months of age. Eight images, with each containing 50 to 100 cells, were randomly obtained per group. The mean neuron/astrocyte ratio of these 8 images was calculated and plotted as 1 data point in the scatter plots. The whole procedure were repeated 3 times; therefore, at least 1000 cells per group were analyzed. The outcomes demonstrated that an age-related shift from neuronal differentiation to astrocytic differentiation was apparent in non-Tg NSCs, as indicated by a decreased number of MAP2+ neurons and an increased number of GFAP+ astrocytes following differentiation (Fig. 2A). Consequently, the derived neuron/astrocyte ratio was lower in 15-month nonTg NSCs $(1.303(0.643<\mu<1.962))$ relative to 3 -month non-Tg NSCs (Fig. 2A, $1.992(0.068<\mu<3.915), p=$ $0.109, n=3)$. The age-dependent decline in the production of new neurons was significantly accelerated in $3 \times \mathrm{TgAD}$ NSCs. Compared to age-matched non-Tg NSCs, a lower neuron/astrocyte differentiation ratio was observed in $3 \mathrm{xTgAD}$ NSCs as early as 3 months of age $(p=0.141, n=$ $3)$, when no overt AD pathology was present [35], and was decreased at 6 months $(p=0.006, n=3)$ and 15 months of age $(p=0.003, n=3)$. The combined effects of age and AD 
Fig. 1 Characterization of neural stem cells derived from adult mice. Second generation of neurospheres (NSs) derived from adult mouse brain (female and male) proliferated and formed neurospheres in proliferation medium as shown in (A) and (B). Majority of adherent monolayer cultures of NS in proliferation medium displayed positive staining for Nestine $(C) ; \beta$ tubulin III (Tuj1, D) was detected in a subset of NSCs. (E, F) Following 5 to 7 days of culture under differentiation conditions, the differentiation capability of NSCs into all 3 neuronal lineages was apparent as indicated by positive staining of MAP2 (E, F, green, neuron marker), GFAP (E, red, astrocyte marker), and MBP ( $\mathrm{F}$, red, oligodendrocyte marker)
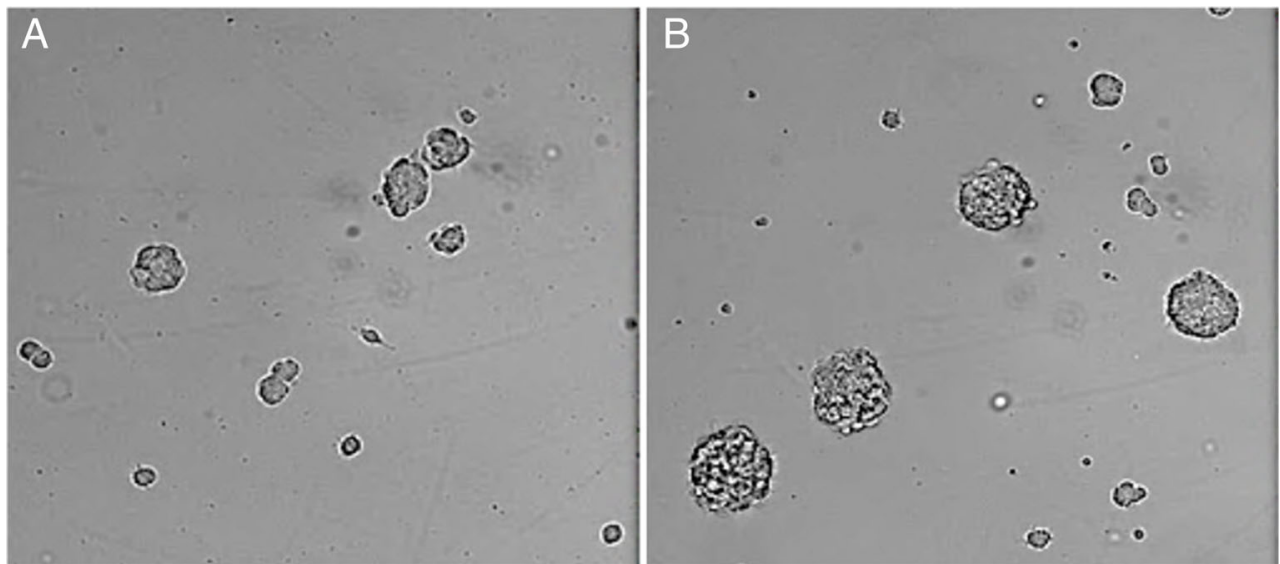

\section{$2^{\text {nd }}$ NS Day 2}

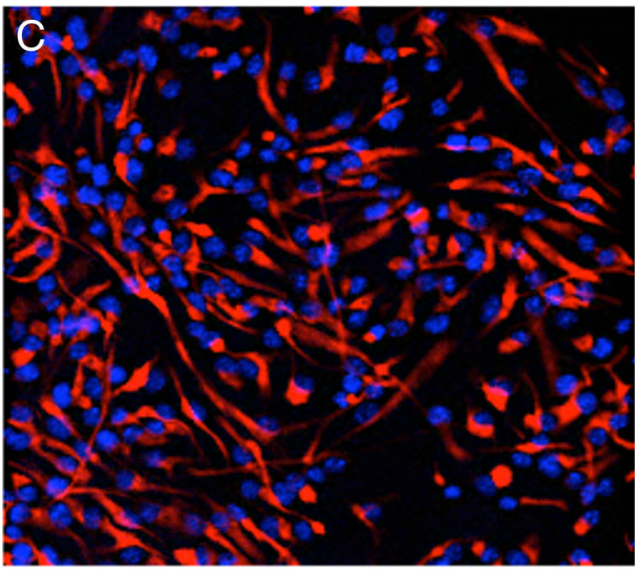

Nestin-DAPI

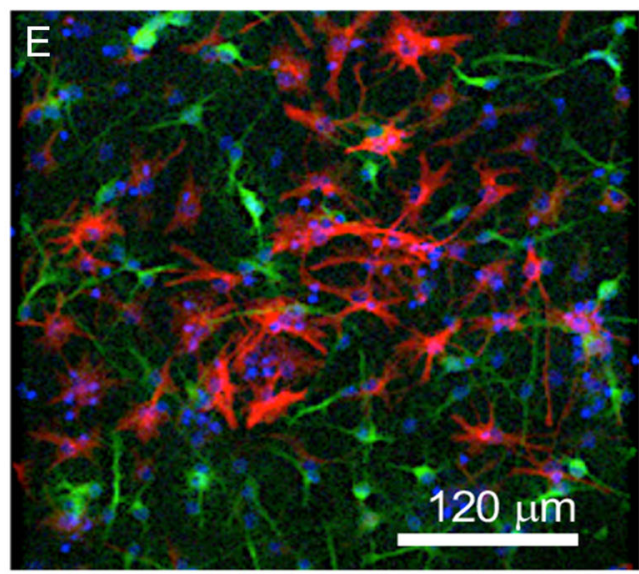

GFAP-MAP2-DAPI $2^{\text {nd }}$ NS Day 4

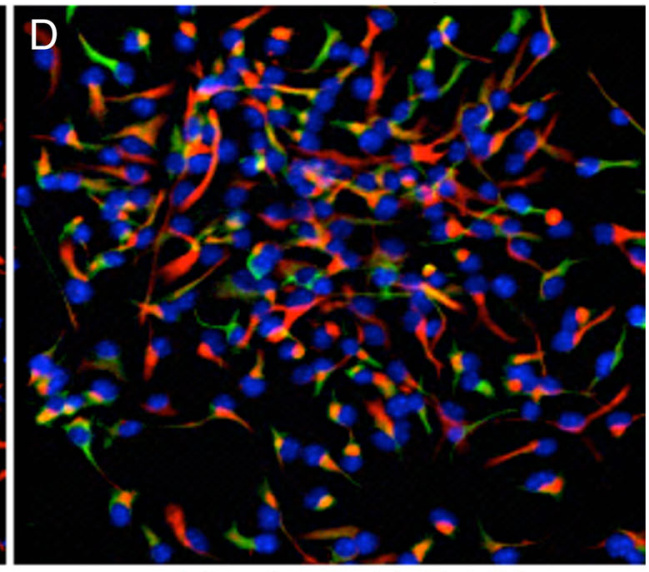

Nestin-Tuj1-DAPI

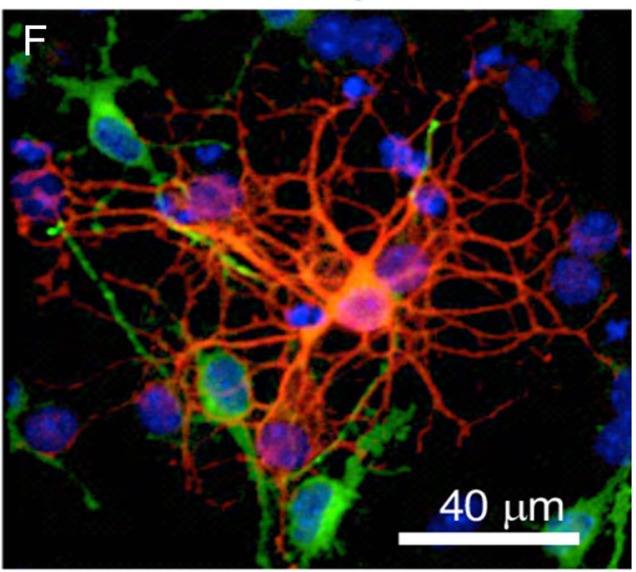

MBP-MAP2-DAPI pathology resulted in a lower neuron/astrocyte differentiation ratio of $3 \times$ TgAD NSCs at 15 months $(0.492(0.0327<\mu<$ $0.658)$ ) compared to 3 months of age $(1.405(0.740<\mu<$ 2.070), $p=0.006, n=3$ ).

Consistent with in vitro results, an age-dependent decline in neurogenesis was observed in both non-Tg and 3xTgAD brains, with more severe deficit in the $3 \times \mathrm{TgAD}$ group (Fig. 2B). Significantly fewer DCX-positive cells were present in hippocampal DG from 6-month- $(p=0.004, n=6)$ and 12-month-old 3xTgAD $(p=0.0002, n=7)$ mice compared to age-matched non-Tg $(n=8-9)$ mice. In 3xTgAD mice, the number of DCX-positive cells was lower at 12 months compared to 6 months of age ( $p=0.024, n=6-7)$.

Together, adult neurogenesis and differentiation were reduced with progressive aging which was accelerated in the Alzheimer's mouse model. 

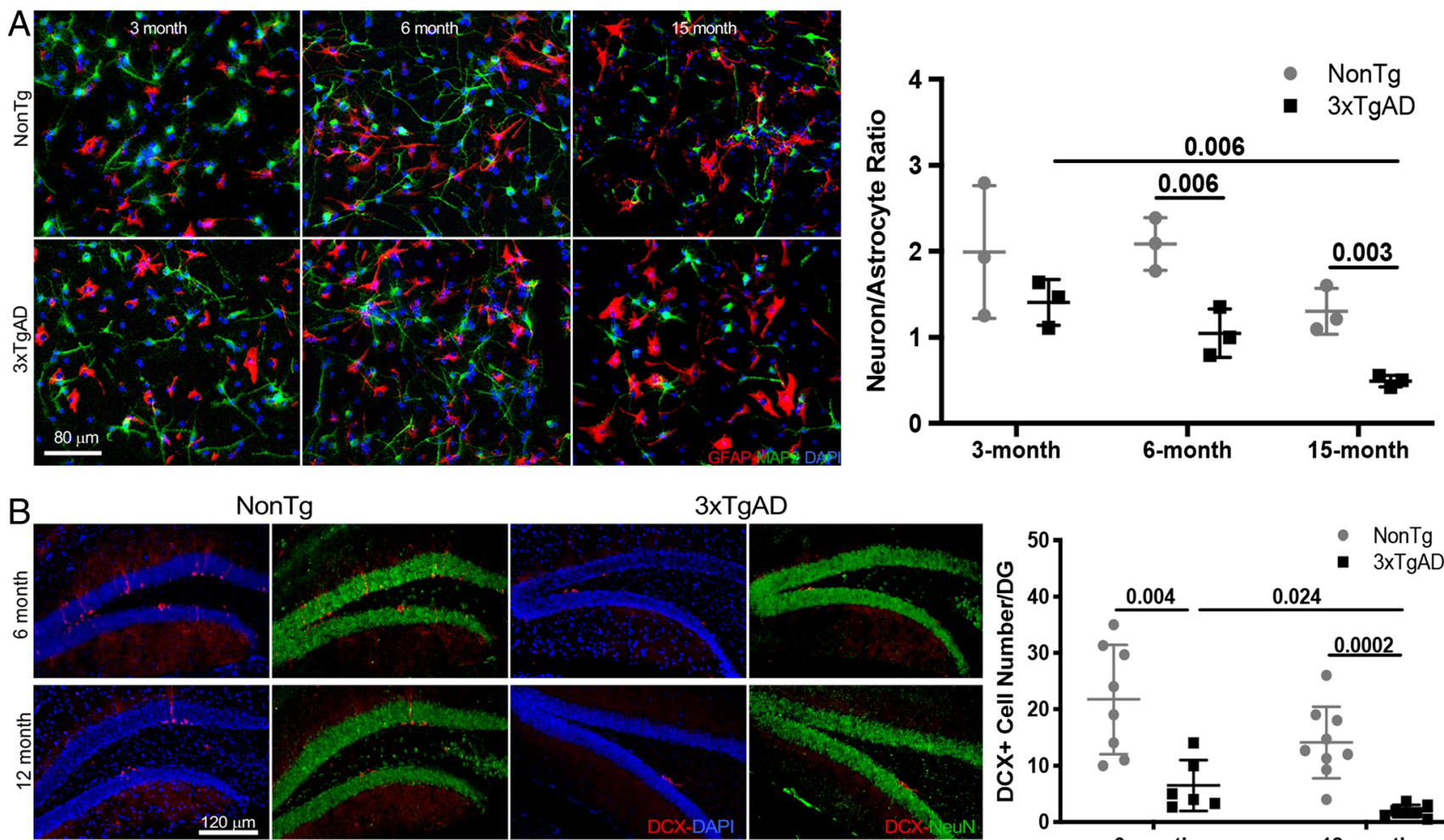

NonTg

$3 \times \operatorname{TgAD}$
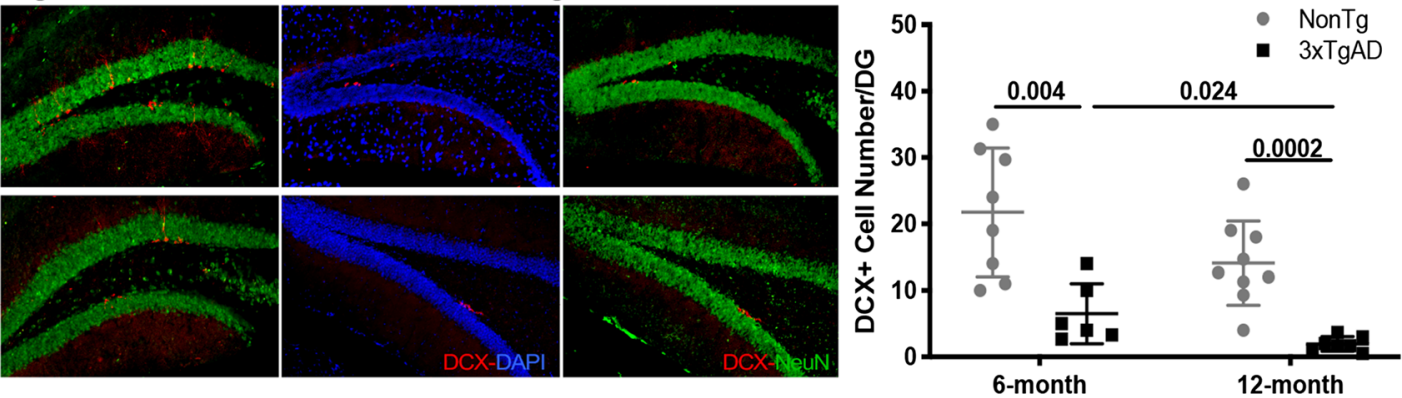

Fig. 2 Age-dependent decline in neuronal differentiation was accelerated in adult 3xTgAD NSCs and brain. (A) Representative images show apparent age-related decline in neuronal differentiation of NSCs derived from 15-month-old non-Tg mice and 6-month-old 3xTgAD mice compared to 3-month-old non-Tg and 3xTgAD NSCs, respectively, as indicated by fewer MAP2+ (green) neurons and more GFAP+ (red) astrocytes. Compared to age-matched non-Tg NSCs, lower neuron/ astrocyte ratio appeared as early as 3 months of age in $3 \times$ TgAD NSCs $(p=0.141, n=3)$ and became obvious at 6 months $(p=0.006, n=3)$ and
15 months $(p=0.003, n=3)$ of age. The neuron/astrocyte ratio was also lower in 15-month 3xTg-NSCs relative to 3-month 3xTgAD NSCs $(p=$ $0.006, n=3)$. (B) Fewer DCX+ (red) cells were present in 6-month- ( $p=$ $0.004, n=6)$ and 12-month-old $(p=0.0002, n=7) 3 \times$ TgAD DG compared to age-matched old nonTg $(n=8-9)$ DG. In 3xTgAD DG, the number of DCX+ cells was also lower at 12 months compared to that at 6 months of age $(p=0.024, n=6-7)$. The scatterplot represents mean values $\pm \mathrm{SD}$

\section{Allopregnanolone Reversed Deficits in Neurogenesis and Neuronal Differentiation in Adult 3xTgAD NSCs}

The effect of Allo on neuronal differentiation was first determined in adult $3 \times \mathrm{TgAD}$ NSCs. The same procedure as mentioned in the section "Age-Dependent Decline in Neuronal Differentiation Was Accelerated in Adult 3xTgAD NSCs and Brain" was performed, and 2000 cells per group were analyzed. Qualitatively, Allo treatment during the differentiation process increased the number of MAP2+ neurons while decreasing the number of GFAP+ astrocytes in 3-month-old $3 \times$ TgAD NSCs compared to the Veh group (Fig. 3A). Quantitatively, the neuron/astrocyte ratio was significantly increased in the Allo-treated group ( $p=0.019, n=5)$ to a level comparable to age-matched non-Tg NSCs (Fig. 2A). The Allo effect on neuronal differentiation was specific to $3 \times \mathrm{TgAD}$ NSCs as the age-matched non-Tg NSCs were not affected (data not shown). Together, Allo reversed the deficits of NSC generation and neuronal differentiation capacity of adult $3 \times$ TgAD NSCs.

\section{Allopregnanolone Enhanced Neuronal Differentiation in 3xTgAD Mice}

To further determine the efficacy of Allo to promote neurogenesis and neuronal differentiation in vivo, 5month-old $3 \times$ TgAD male mice were treated with $10 \mathrm{mg} / \mathrm{kg}$ of Allo for 2 weeks and assessed at 6 months of age. Allo treatment increased the number of newly generated immature neurons $(\mathrm{BrdU}+/ \mathrm{DCX}+)$ in both SGZ of the hippocampal DG (Fig. 4A) and SVZ (Fig. $4 \mathrm{~B})$ of $3 \times \mathrm{TgAD}$ mice. Consistent with immuno-imaging data, DCX protein expression was increased by $30 \%$ in Allo-treated brain (Fig. 4C, $p=0.040, n=5$ ). These results indicate that Allo promotes neurogenesis in $3 \times T g A D$ mice, replicating our earlier findings [28-30].

Increased neurogenesis could be due to increasing the number of NSCs or by increasing NSCs undergoing neuronal differentiation or both. To address these possibilities, the composition of newly generated cells was analyzed by flow cytometry. Relative to the Veh group, the 


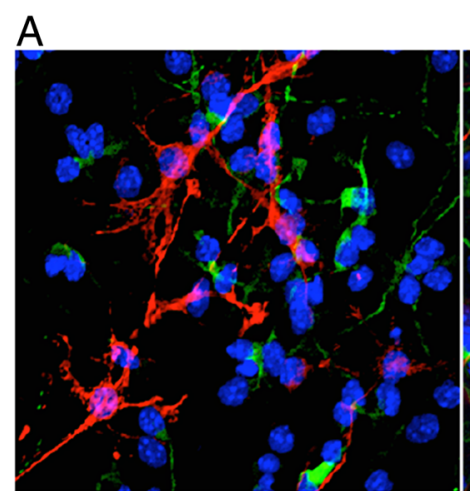

Vehicle

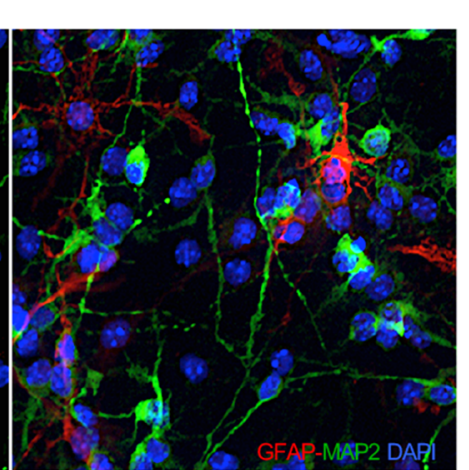

Allo (100nM)

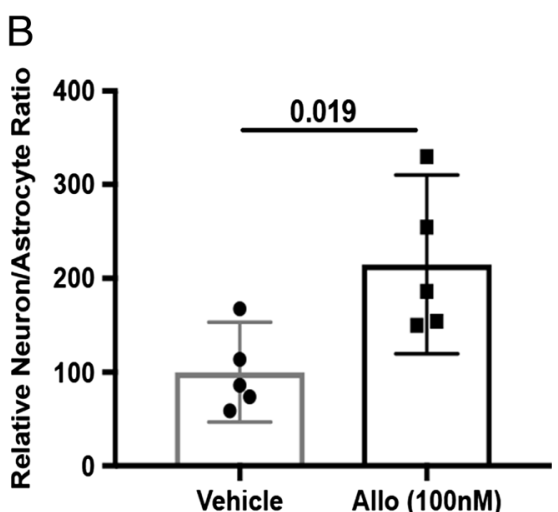

$100 \%(46.9 \%<\mu<153.1 \%)$ of vehicle group to $215 \%(119.7 \%<\mu<$ $310.2 \%)$ of Allo group $(p=0.019, n=5)$. The scatterplot represents mean values $\pm 95 \%$ CI.

\section{Allopregnanolone Upregulated IGF-1 and IGF-1 Receptor Expression in 3xTgAD Mouse Brain}

Growth factors are key regulators of brain neurogenesis during CNS development and adulthood [36]. We therefore investigated the impact of Allo on the expression of 2 major growth factors in the brain, IGF-1 and brain-derived neurotrophic factor (BDNF). Allo treatment increased IGF-1 (Fig. 7A, $p=0.142, n=5$ ) and IGF-1R protein levels (Fig. $7 \mathrm{~B}, p=0.047, n=5$ ) compared to the vehicle group (Fig. $7 \mathrm{~A}, \mathrm{~B}, n=5$ ). Increased immunoreactivity of IGF-1 and IGF-1R was also detected in the hippocampus and frontal cortex in Allo-treated 3xTgAD mice (Fig. 7C, D). In contrast, the protein level of BDNF was not affected by Allo treatment (data not shown), further confirming the specific upregulation of IGF-1 in Allo-treated 3xTgAD mice. These findings suggest that Allo-induced neurogenesis is associated with IGF-1 and IGF-1R signaling.

\section{Allopregnanolone Promoted Oligodendrogenesis in 3xTgAD Mice}

Earlier findings indicated increased myelination in the Allo-treated 3xTgAD brain [30]. Based on these findings, an analysis of the Allo effect on oligodendrocyte precursor generation was conducted. As shown in Fig. 6, Allo treatment stimulated oligodendrogenesis in the $3 \times \mathrm{TgAD}$ brain in vivo, as indicated by increased numbers of Olig2-positive cells in the corpus callosum area (Fig. 6A). Consistent with the cellular analysis, Olig2 protein expression was significantly increased by $29 \%$ in the Allo-treated group (Fig. 6B, $p=0.008, n=5$ ). These results demonstrated that Allo treatment promoted oligodendrogenesis in the adult $3 \times \mathrm{TgAD}$ brain in vivo, which would be predictive of increased remyelination.

\section{Discussion}

Our previous analysis demonstrated Allo increased proliferation of neural stem/neural progenitor cells in vitro and in vivo [28-30]. In female mice, hippocampal neurogenesis is strongly affected by the fluctuated circulating levels of steroid hormones across the estrous cycle, particularly estradiol [37]. Adult NSC proliferation increased transiently during proestrus when estrogen levels are high. This cyclic variation confounds the therapeutic evaluation of exogenous Allo's effect. Ovariectomy is a common strategy to reduce circulating levels of endogenous estrogens and was instituted previously in our investigation of Allo in females in which improved mitochondrial function, reduced lipid peroxidation, and downregulation 


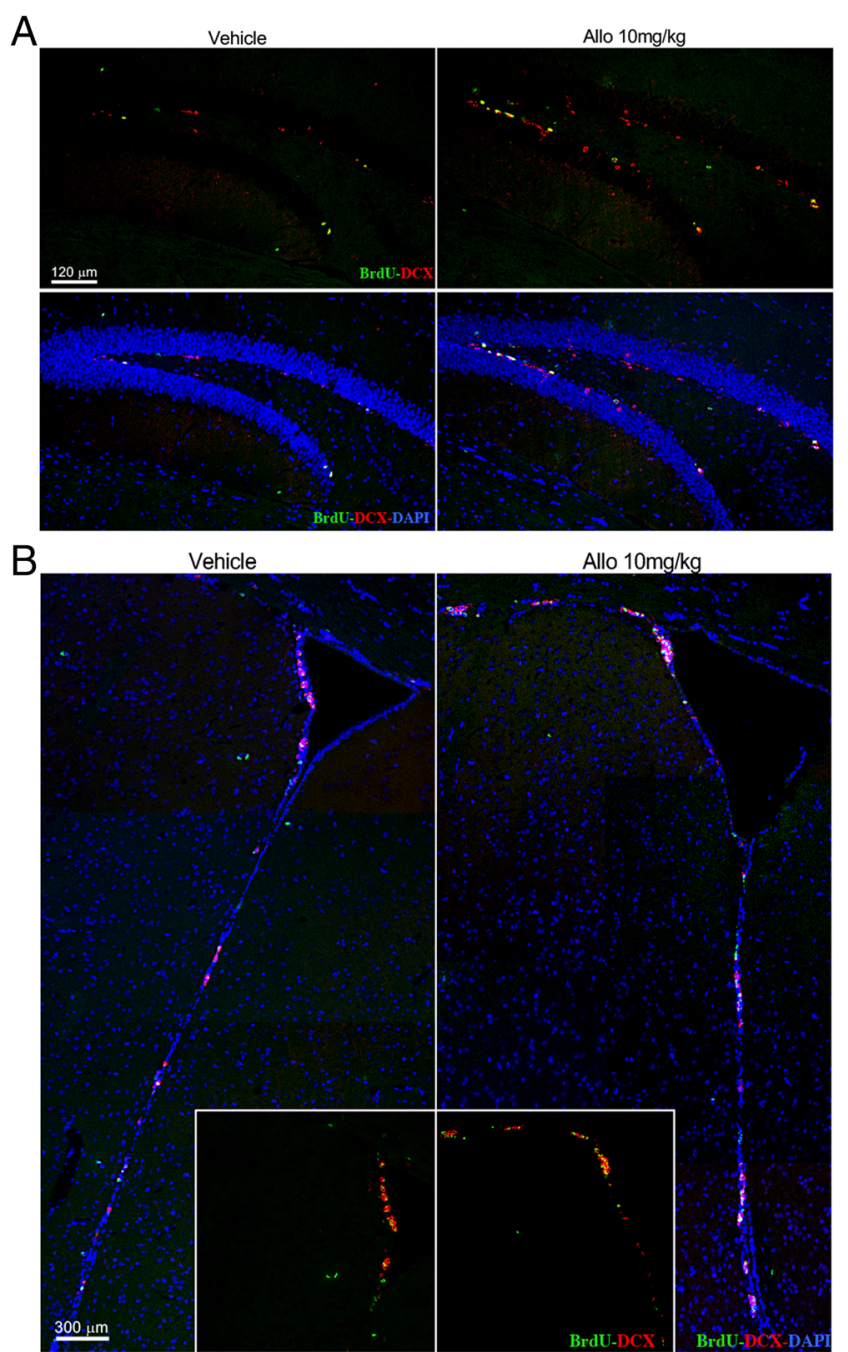

C

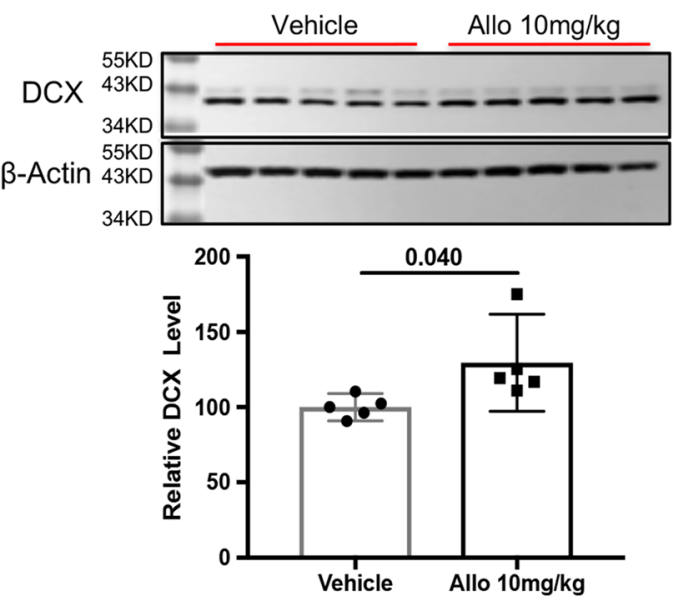

Fig. 4 Allopregnanolone increased neurogenesis in 3xTgAD mice. Allo treatment increased the number of immature neurons $(B r d U+D C X+)$ in both hippocampal DG (A) and SVZ (B) of 3xTgAD mice. (C) Western blot assay confirmed that Allo treatment increased DCX protein expression by $30 \%(129.6 \%(97.27 \%<\mu<162 \%))$ compared to Veh group $(100 \%(90.9 \%<\mu<109.1 \%), p=0.040, n=5)$. The scatterplot represents mean values $\pm 95 \% \mathrm{CI}$ of genes involved in Alzheimer's pathology were observed [38].

In the current analysis, we further demonstrated Allo treatment restored the neurogenic and neuronal differentiation capacity of aged male 3xTgAD mice to age-associated normal. Allo treatment also enhanced oligodendrogenesis in male $3 x$ TgAD mice. This increase of differentiation to neurons and oligodendrocytes was paralleled by an increase in IGF-1 and IGF-1R expression levels.

\section{Allopregnanolone Reversed Aging and AD-Related Deficits in Neurogenesis of 3xTgAD Mice}

Although adult neurogenesis occurs throughout life [39-41], neurogenic capacity decreases with aging and was severely impaired in neurodegenerative diseases [18, 29]. Compared to young adult mice, neuronal differentiation of NSCs in aged mice declines and astrocytic differentiation increases, which is accompanied by the decreased survival of newly generated neurons $[42,43]$. In 3xTgAD mice, we and other labs reported severe disease-dependent decline in neurogenesis with aging $[18,29]$. In current study, we demonstrated that the agedependent shift from neuronal to glial differentiation was significantly accelerated in 3xTgAD adult NSCs, which was further supported by the decline in immature neuron numbers with aging in $3 \times T$ TgD mice. Allo treatment restored the neuronal differentiation capacity of adult 3xTgAD NSCs in vitro and promoted both neuronal proliferation and differentiation in 3xTgAD brains in vivo. These findings extend the understanding of Allo's impact on neurogenesis, and provide preclinical evidence for Allo as a therapeutic to promote adult neural cell regeneration in $\mathrm{AD}$ conditions.

\section{Allopregnanolone Promotes Oligodendrogenesis in 3xTgAD Mice}

White matter abnormalities have been widely reported in AD patient brains; detectable changes appear in early stages, and the degeneration of white matter networks correlates with cognitive decline [23-25, 44]. This disease phenotype is recapitulated in the $3 \times \operatorname{TgAD}$ mouse model, in which abnormal myelination and loss of axonal integrity occur in the same

Fig. 5 Allo promoted neuronal differentiation in $3 \times \mathrm{TgAD}$ mice. (A) Representative flow cytometry results show BrdU+ and BrdU+/NeuN+ populations in Veh and Allo-treated group. (B) Allo treatment increased the percentage of BrdU+ nuclei compared to Veh group $(p=0.007, n=$ 5). (C) Allo treatment increased the percent of BrdU+/NeuN+ nuclei compared to Veh group $(p=0.001, n=4)$. (D) The $\mathrm{BrdU}+/ \mathrm{NeuN}+$ to BrdU+ ratio was increased in Allo-treated group $(p=0.004, n=4)$. Immunostaining on brain sections revealed increased BrdU+ cells double-labeled with NeuN and not GFAP in both hippocampal DG (E) and SVZ (F) of Allo-treated 3xTgAD mice. The scatterplot represents mean values $\pm 95 \%$ CI 

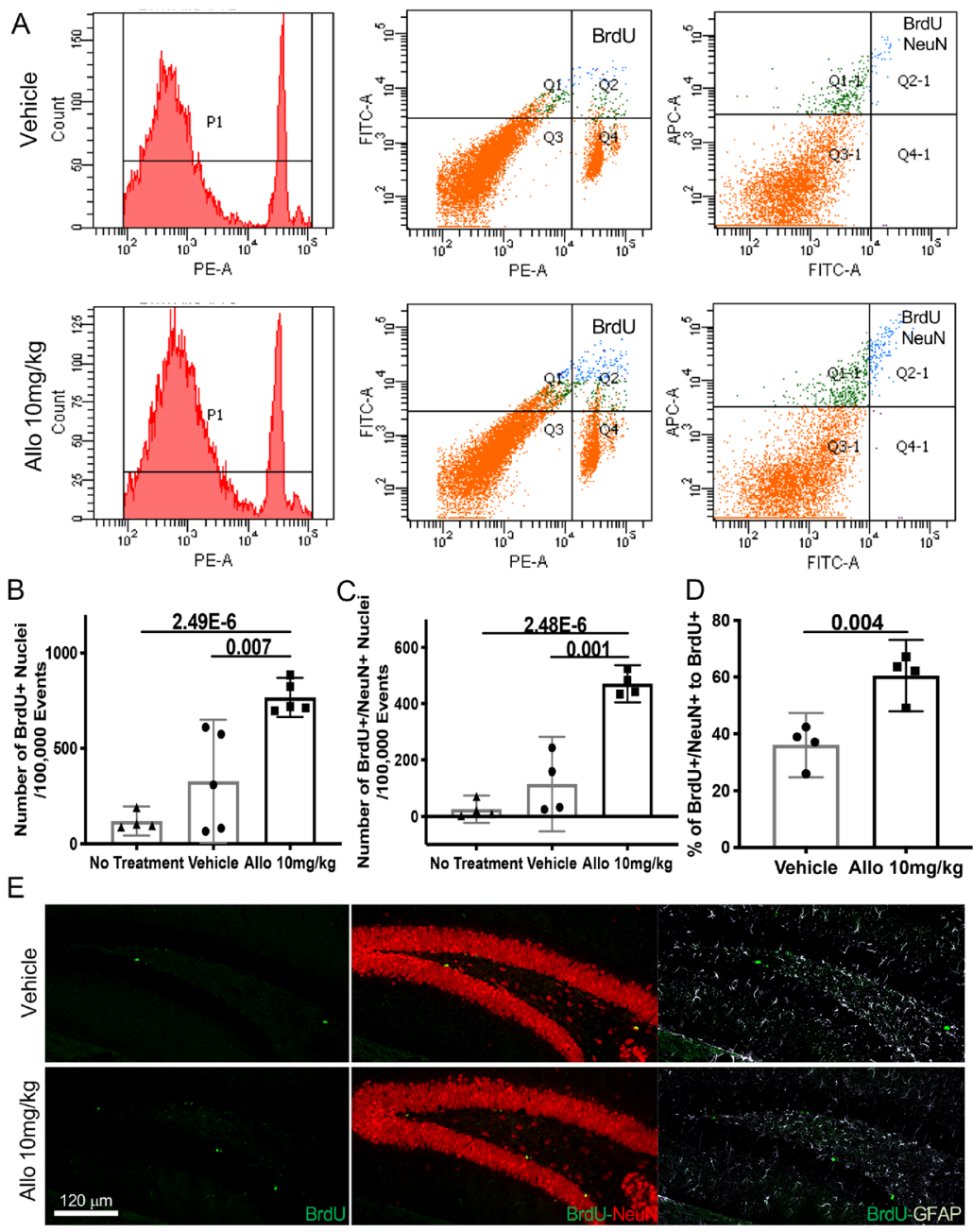

F

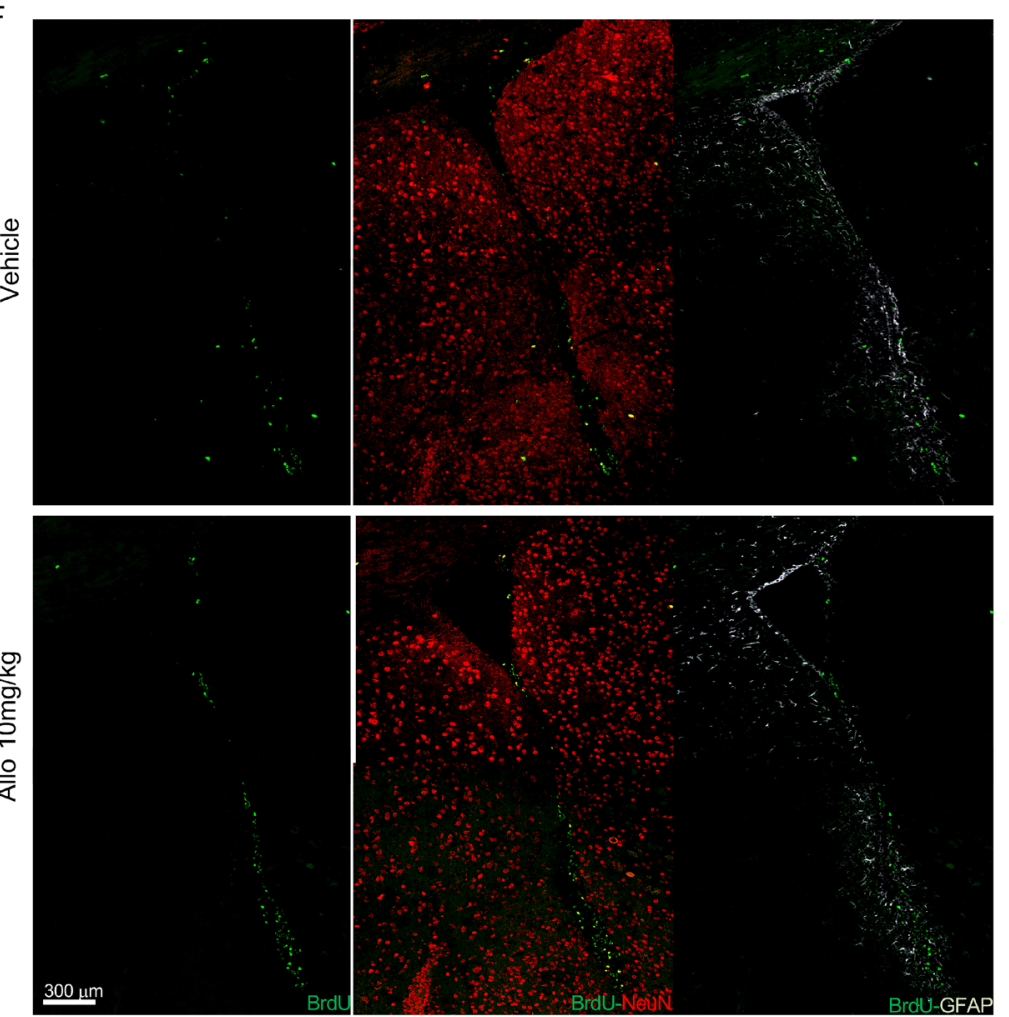


Fig. 6 Allo treatment promotes oligodendrogenesis in 3xTgAD mice. (A) Allo treatment increased Olig2+ cells in frontal cortex corpus callosum area of 3xTgAD mice. (B) Allo treatment increased Olig2 protein level by $29 \%(129.3 \%(107.9 \%<\mu<$ $150.7 \%)$ ) compared to Veh group $(100 \%(91.4 \%<\mu<108.7 \%)$, $p=0.008, n=5$ ). The scatterplot represents mean values $\pm 95 \% \mathrm{Cl}$

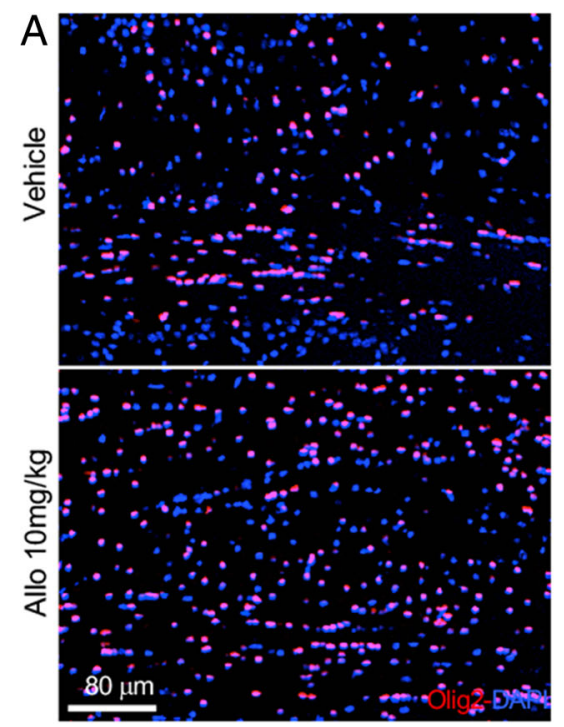

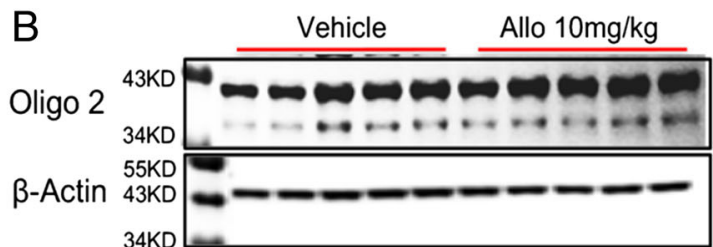

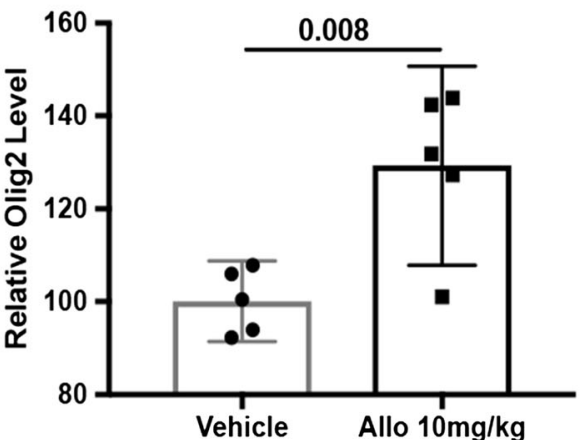

brain regions vulnerable to AD pathology in humans [27]. Our results indicated that Allo treatment induced a significant
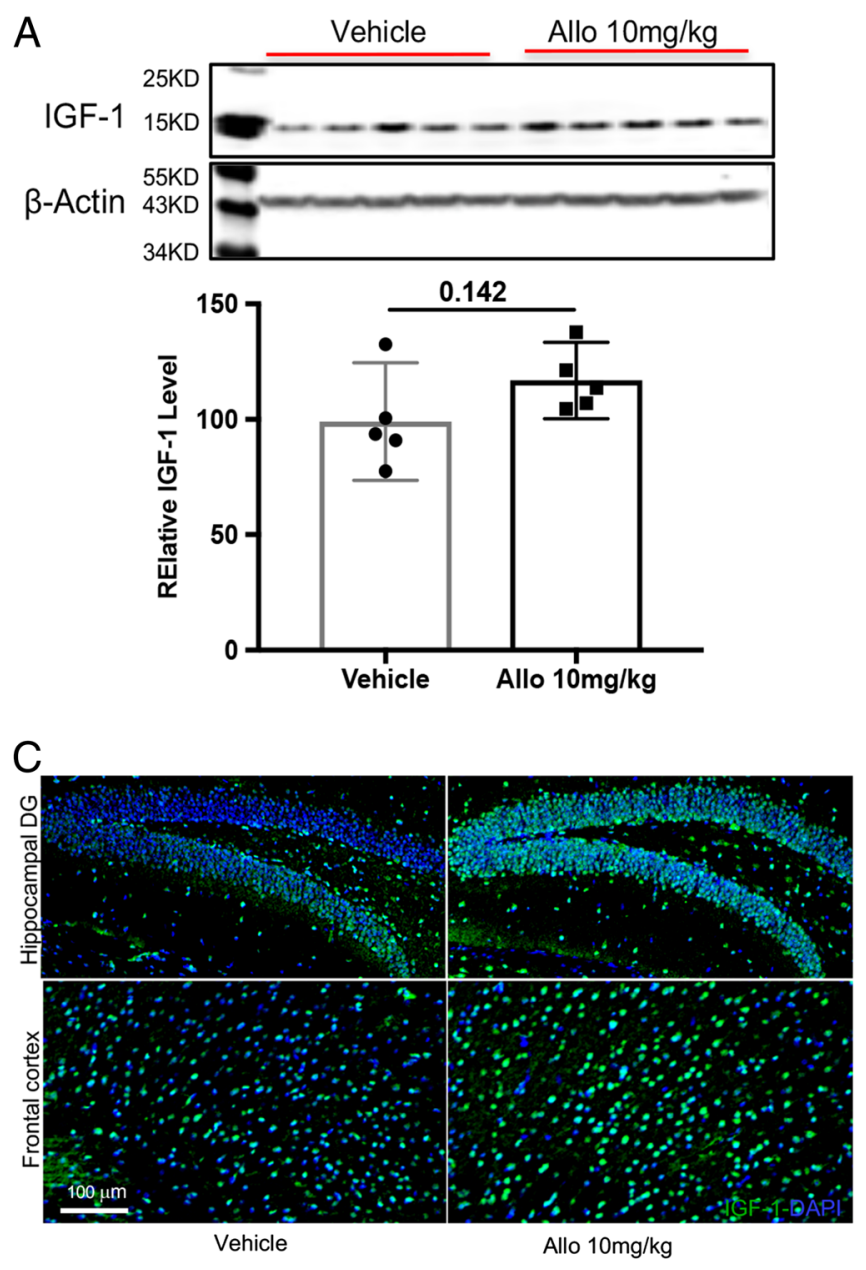

Fig. 7 Allopregnanolone enhanced expression of IGF-1 and IGF-1R in 3xTgAD mice. Allo treatment increased hippocampal IGF-1 (A, $p=$ $0.142, n=5)$ and IGF-1R (B, $p=0.047, n=5)$ protein levels compared to vehicle group. Representative images revealed that stronger increase in Olig2 protein levels as well as Olig2+ oligodendrocyte numbers in the frontal cortex region in $3 \times \mathrm{TgAD}$

B
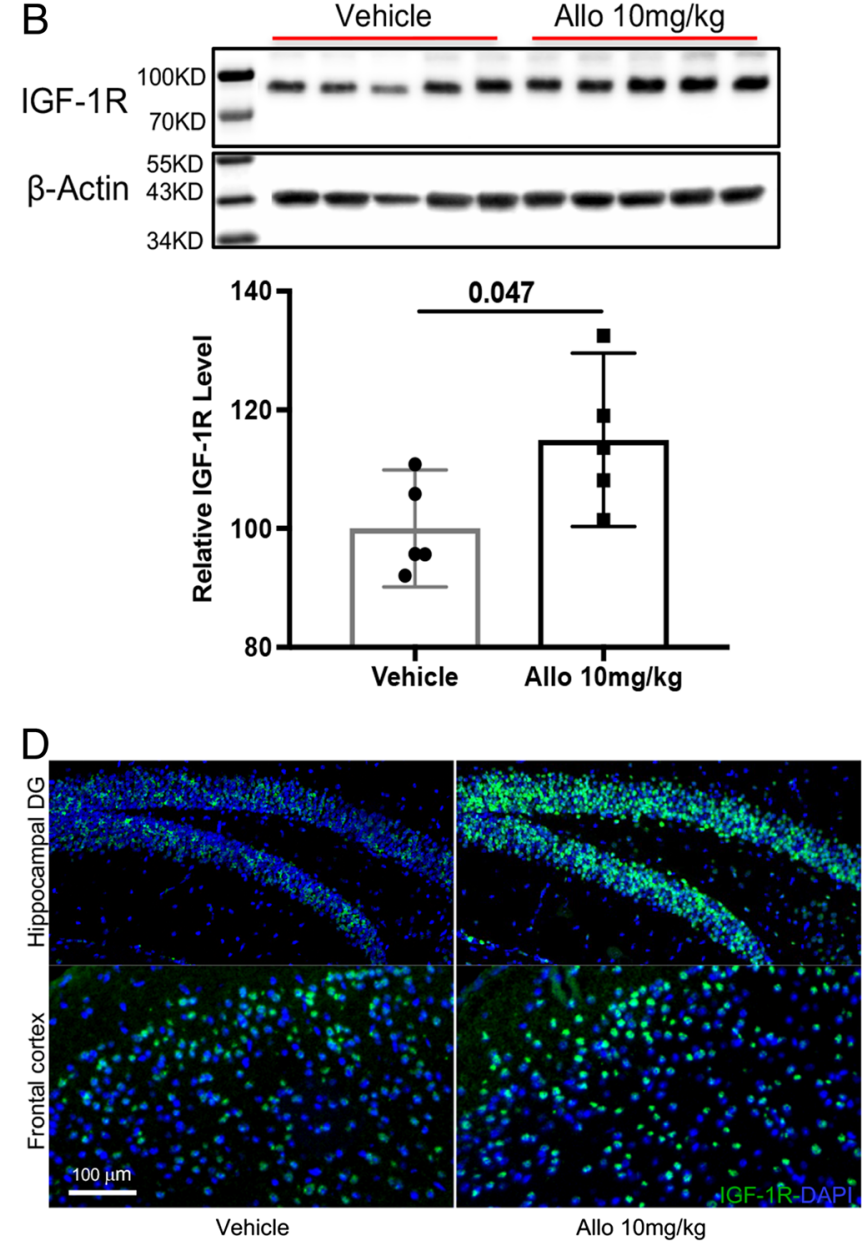

immunoreactivity of IGF-1 (C) and IGF-1R (D) were observed in hippocampus and frontal cortex of Allo-treated 3xTgAD mice. The scatterplot represents mean values $\pm 95 \%$ CI 
mouse brains. This finding explained the increase in nonneuronal progenitor cell numbers in the Allo-treated group (Fig. 5B), which is consistent with our previous work demonstrating that 6 months of weekly Allo treatment significantly increased myelination in hippocampal, entorhinal cortex, and primary somatosensory cortex regions of $3 \mathrm{xTgAD}$ mice [45]. Our findings are consistent with those of Schumacher et al. [46-48] who reported an increase in oligodendrogenesis and endogenous remyelination by oligodendrocytes with progesterone treatment. Given that Allo is a metabolite of progesterone, it is possible that the oligodendrogenesis effects of progesterone may be, at least partially, mediated through Allo.

\section{IGF-1 Mediated Allo-Induced Neuronal Proliferation and Differentiation}

IGF-1 is a key growth factor regulating adult neurogenesis by driving cellular processes such as proliferation, differentiation, and migration [49], and also plays a pivotal role in oligodendrocyte differentiation and myelingenesis [50]. Our results demonstrated that Allo treatment increased IGF-1 and IGF-1R levels but not BDNF levels in 3xTgAD mouse brains, which was paralleled with restoration of neurogenesis and promoted oligodendrogenesis in the brain. Baykara et al. [51] previously reported that increased serum IGF-1 levels correlated with the increased neuron density following progesterone treatment in the traumatic brain injury model. Further, the Allo-induced increase in IGF-1 is consistent with our previous findings that Allo treatment increased gene expression levels of Akt and mTOR in ovariectomized 3xTgAD mice [38], both of which were downstream targets of the IGF-1 pathway [52-54]. Collectively, these results suggest that the IGF-1/PI3K/ AKT pathway plays an important role in mediating Allo-induced neurogenesis and oligodendrogenesis.

Collectively, our findings demonstrate that Allo promotes regeneration and differentiation of NSCs and enhances oligodendrogenesis. Further, our findings replicated earlier findings regarding the neurogenic effect of Allo in Alzheimer's mouse model brain [28-30]. Results reported herein extend the mechanistic understanding of Allo action to restore neurogenic and cognitive function in male $3 \mathrm{xTgAD}$ mice. Collectively, these studies provide mechanistic and preclinical evidence for Allo as a pleiotropic systemslevel regenerative therapeutic for the prevention and treatment of Alzheimer's disease.

Acknowledgments This research was supported by grants from the National Institute on Aging U01-AG031115, U01-AG047222, UF1AG046148, and P01-AG026572 to Roberta Diaz Brinton.

Required Author Forms Disclosure forms provided by the authors are available with the online version of this article.

\section{References}

1. Irwin RW, Brinton RD. Allopregnanolone as regenerative therapeutic for Alzheimer's disease: translational development and clinical promise. Prog Neurobiol 2014;113:40-55.

2. Moreno-Jimenez EP, Flor-Garcia M, Terreros-Roncal J, Rabano A, Cafini F, Pallas-Bazarra N, et al. Adult hippocampal neurogenesis is abundant in neurologically healthy subjects and drops sharply in patients with Alzheimer's disease. Nat Med 2019;25(4):554-60.

3. Altman J, Das GD. Autoradiographic and histological evidence of postnatal hippocampal neurogenesis in rats. J Comp Neurol 1965;124(3):319-35.

4. Cameron HA, McKay RD. Adult neurogenesis produces a large pool of new granule cells in the dentate gyrus. J Comp Neurol 2001;435(4):406-17.

5. Cameron HA, Woolley CS, McEwen BS, Gould E. Differentiation of newly born neurons and glia in the dentate gyrus of the adult rat. Neuroscience 1993;56(2):337-44.

6. Altman J. Autoradiographic and histological studies of postnatal neurogenesis. IV. Cell proliferation and migration in the anterior forebrain, with special reference to persisting neurogenesis in the olfactory bulb. J Comp Neurol 1969;137(4):433-57.

7. Luskin MB. Restricted proliferation and migration of postnatally generated neurons derived from the forebrain subventricular zone. Neuron 1993;11(1):173-89.

8. Cameron HA, Dayer AG. New interneurons in the adult neocortex: small, sparse, but significant? Biol Psychiatry 2008;63(7):650-5.

9. Kokoeva MV, Yin H, Flier JS. Evidence for constitutive neural cell proliferation in the adult murine hypothalamus. J Comp Neurol 2007;505(2):209-20.

10. Lee A, Kessler JD, Read TA, Kaiser C, Corbeil D, Huttner WB, et al. Isolation of neural stem cells from the postnatal cerebellum. Nat Neurosci 2005;8(6):723-9.

11. Ponti G, Peretto P, Bonfanti L. Genesis of neuronal and glial progenitors in the cerebellar cortex of peripuberal and adult rabbits. PLoS One. 2008;3(6):e2366.

12. Morgenstern NA, Lombardi G, Schinder AF. Newborn granule cells in the ageing dentate gyrus. J Physiol 2008;586(16):3751-7.

13. Cameron HA, McKay RD. Restoring production of hippocampal neurons in old age. Nat Neurosci 1999;2(10):894-7.

14. Jin K, Sun Y, Xie L, Batteur S, Mao XO, Smelick C, et al. Neurogenesis and aging: FGF-2 and HB-EGF restore neurogenesis in hippocampus and subventricular zone of aged mice. Aging Cell 2003;2(3):175-83.

15. Kuhn HG, Dickinson-Anson H, Gage FH. Neurogenesis in the dentate gyrus of the adult rat: age-related decrease of neuronal progenitor proliferation. JN Neuroci 1996;16(6):2027-33.

16. Drapeau E, Mayo W, Aurousseau C, Le Moal M, Piazza PV, Abrous DN. Spatial memory performances of aged rats in the water maze predict levels of hippocampal neurogenesis. Proceedings of the National Academy of Sciences of the United States of America 2003;100(24):14385-90.

17. Siwak-Tapp CT, Head E, Muggenburg BA, Milgram NW, Cotman $\mathrm{CW}$. Neurogenesis decreases with age in the canine hippocampus and correlates with cognitive function. Neurobiology of learning and memory. 2007;88(2):249-59.

18. Rodriguez JJ, Verkhratsky A. Neurogenesis in Alzheimer's disease. J Anat. 2011;219(1):78-89.

19. Selkoe DJ. Alzheimer's disease results from the cerebral accumulation and cytotoxicity of amyloid beta-protein. J Alzheimers Dis. 2001;3(1):75-80.

20. Masliah E, Mallory M, Hansen L, DeTeresa R, Alford M, Terry R. Synaptic and neuritic alterations during the progression of Alzheimer's disease. Neurosci Lett. 1994;174(1):67-72. 
21. van Praag H, Schinder AF, Christie BR, Toni N, Palmer TD, Gage FH. Functional neurogenesis in the adult hippocampus. Nature. 2002;415(6875):1030-4.

22. Brinton RD. Neurosteroids as regenerative agents in the brain: therapeutic implications. Nature reviews Endocrinology. 2013;9(4): 241-50.

23. Bartzokis G. Age-related myelin breakdown: a developmental model of cognitive decline and Alzheimer's disease. Neurobiol Aging 2004;25(1):5-18; author reply 49-62.

24. Bartzokis G, Cummings JL, Sultzer D, Henderson VW, Nuechterlein KH, Mintz J. White matter structural integrity in healthy aging adults and patients with Alzheimer disease: a magnetic resonance imaging study. Archives of neurology 2003;60(3): 393-8.

25. Bartzokis G, Lu PH, Tingus K, Mendez MF, Richard A, Peters DG, et al. Lifespan trajectory of myelin integrity and maximum motor speed. Neurobiol Aging 2010;31(9):1554-62.

26. Oddo S, Caccamo A, Shepherd JD, Murphy MP, Golde TE, Kayed $\mathrm{R}$, et al. Triple-transgenic model of Alzheimer's disease with plaques and tangles: intracellular Abeta and synaptic dysfunction. Neuron 2003;39(3):409-21.

27. Desai MK, Sudol KL, Janelsins MC, Mastrangelo MA, Frazer ME, Bowers WJ. Triple-transgenic Alzheimer's disease mice exhibit region-specific abnormalities in brain myelination patterns prior to appearance of amyloid and tau pathology. Glia 2009;57(1):54-65.

28. Wang JM, Johnston PB, Ball BG, Brinton RD. The neurosteroid allopregnanolone promotes proliferation of rodent and human neural progenitor cells and regulates cell-cycle gene and protein expression. J Neurosci 2005;25(19):4706-18.

29. Wang JM, Singh C, Liu L, Irwin RW, Chen S, Chung EJ, et al. Allopregnanolone reverses neurogenic and cognitive deficits in mouse model of Alzheimer's disease. Proc Natl Acad Sci U S A 2010;107(14):6498-503.

30. Chen S, Wang JM, Irwin RW, Yao J, Liu L, Brinton RD. Allopregnanolone promotes regeneration and reduces $\beta$-amyloid burden in a preclinical model of Alzheimer's disease. PLoS One 2011;6(8):e24293.

31. Schumacher M, Guennoun R, Robert F, Carelli C, Gago N, Ghoumari A, et al. Local synthesis and dual actions of progesterone in the nervous system: neuroprotection and myelination. Growth Hormone \& Igf Research 14 Suppl A. 2004:S18-33,

32. Mellon SH, Gong W, Schonemann MD. Endogenous and synthetic neurosteroids in treatment of Niemann-Pick Type $\mathrm{C}$ disease. Brain Res Rev. 2008;57(2):410-20.

33. Singh C, Liu L, Wang JM, Irwin RW, Yao J, Chen S, et al. Allopregnanolone restores hippocampal-dependent learning and memory and neural progenitor survival in aging $3 \times \mathrm{TgAD}$ and nonTg mice. Neurobiol Aging. 2012;33(8):1493-506.

34. Heinlein C, Deppert W, Braithwaite AW, Speidel D. A rapid and optimization-free procedure allows the in vivo detection of subtle cell cycle and ploidy alterations in tissues by flow cytometry. Cell Cycle. 2010;9(17):3584-90.

35. Oddo S, Caccamo A, Kitazawa M, Tseng BP, LaFerla FM. Amyloid deposition precedes tangle formation in a triple transgenic model of Alzheimer's disease. Neurobiol Aging. 2003;24(8):106370 .

36. Zhao C, Deng W, Gage FH. Mechanisms and functional implications of adult neurogenesis. Cell. 2008;132(4):645-60.

37. Pawluski JL, Brummelte S, Barha CK, Crozier TM, Galea LA. Effects of steroid hormones on neurogenesis in the hippocampus of the adult female rodent during the estrous cycle, pregnancy, lactation and aging. Front Neuroendocrinol. 2009;30(3):343-57.

38. Wang T, Yao J, Chen S, Mao Z, Brinton RD. Allopregnanolone reverses bioenergetic deficits in female triple transgenic Alzheimer's mouse model. . Neurotherapeutics. 2019.
39. Ernst A, Alkass K, Bernard S, Salehpour M, Perl S, Tisdale J, et al. Neurogenesis in the striatum of the adult human brain. Cell. 2014;156(5):1072-83.

40. Knoth R, Singec I, Ditter M, Pantazis G, Capetian P, Meyer RP, et al. Murine features of neurogenesis in the human hippocampus across the lifespan from 0 to 100 years. PLoS One. 2010;5(1): e8809.

41. Spalding KL, Bergmann O, Alkass K, Bernard S, Salehpour M, Huttner HB, et al. Dynamics of hippocampal neurogenesis in adult humans. Cell. 2013;153(6):1219-27.

42. Lee SW, Clemenson GD, Gage FH. New neurons in an aged brain. Behav Brain Res. 2012;227(2):497-507.

43. Katsimpardi L, Lledo PM. Regulation of neurogenesis in the adult and aging brain. Curr Opin Neurobiol. 2018;53:131-8.

44. Kuczynski B, Reed B, Mungas D, Weiner M, Chui HC, Jagust W. Cognitive and anatomic contributions of metabolic decline in Alzheimer disease and cerebrovascular disease. Archives of neurology. 2008;65(5):650-5.

45. Chen S, Wang JM, Irwin RW, Yao J, Liu L, Brinton RD. Allopregnanolone promotes regeneration and reduces betaamyloid burden in a preclinical model of Alzheimer's disease. PLoS One. 2011;6(8):e24293.

46. El-Etr M, Rame M, Boucher C, Ghoumari AM, Kumar N, Liere P, et al. Progesterone and nestorone promote myelin regeneration in chronic demyelinating lesions of corpus callosum and cerebral cortex. Glia. 2015;63(1):104-17.

47. Schumacher M, Hussain R, Gago N, Oudinet JP, Mattern C, Ghoumari AM. Progesterone synthesis in the nervous system: implications for myelination and myelin repair. Front Neurosci. 2012;6:10.

48. Schumacher M, Mattern C, Ghoumari A, Oudinet JP, Liere P, Labombarda F, et al. Revisiting the roles of progesterone and allopregnanolone in the nervous system: resurgence of the progesterone receptors. Prog Neurobiol. 2014;113:6-39.

49. Nieto-Estevez V, Defterali C, Vicario-Abejon C. IGF-I: a key growth factor that regulates neurogenesis and synaptogenesis from embryonic to adult stages of the brain. Front Neurosci. 2016;10:52.

50. Chesik D, De Keyser J, Wilczak N. Insulin-like growth factor system regulates oligodendroglial cell behavior: therapeutic potential in CNS. J Mol Neurosci. 2008;35(1):81-90.

51. Baykara B, Aksu I, Buyuk E, Kiray M, Sisman AR, Baykara B, et al. Progesterone treatment decreases traumatic brain injury induced anxiety and is correlated with increased serum IGF-1 levels; prefrontal cortex, amygdala, hippocampus neuron density; and reduced serum corticosterone levels in immature rats. Biotech Histochem. 2013;88(5):250-7.

52. Mairet-Coello G, Tury A, DiCicco-Bloom E. Insulin-like growth factor-1 promotes $\mathrm{G}(1) / \mathrm{S}$ cell cycle progression through bidirectional regulation of cyclins and cyclin-dependent kinase inhibitors via the phosphatidylinositol 3-kinase/Akt pathway in developing rat cerebral cortex. The Journal of neuroscience : the official journal of the Society for Neuroscience. 2009;29(3):775-88.

53. Otaegi G, Yusta-Boyo MJ, Vergano-Vera E, Mendez-Gomez HR, Carrera AC, Abad JL, et al. Modulation of the PI 3-kinase-Akt signalling pathway by IGF-I and PTEN regulates the differentiation of neural stem/precursor cells. J Cell Sci. 2006;119(Pt 13):2739-48.

54. Yuan H, Chen R, Wu L, Chen Q, Hu A, Zhang T, et al. The regulatory mechanism of neurogenesis by IGF-1 in adult mice. Mol Neurobiol. 2015;51(2):512-22.

Publisher's Note Springer Nature remains neutral with regard to jurisdictional claims in published maps and institutional affiliations. 